\title{
Characteristics and Causes of Extreme Rainfall Induced by Binary Tropical Cyclones over China
}

\author{
Mingyang Wang ${ }^{1,2} \cdot$ Fumin $\mathrm{Ren}^{2} \cdot$ Yanjun $\mathrm{Xie}^{3} \cdot$ Guoping $\mathrm{Li}^{1} \cdot$ Ming-Jen Yang ${ }^{4} \cdot$ Tian Feng ${ }^{1,2}$
}

Received: 8 November 2019 / Revised: 28 March 2020 / Accepted: 29 March 2020 / Published online: 21 April 2020

(C) The Author(s) 2020

\begin{abstract}
Binary tropical cyclones (BTC) often bring disastrous rainfall to China. From the viewpoint of the extreme of the BTC maximum daily rainfall, the characteristics of BTC extreme rainfall (BTCER) during 1960-2018 are analyzed, using daily rainfall data; and some representative large-scale mean flows, in which the associated BTCs are embedded, are analyzed. Results show that the frequency of BTCER shows a decreasing trend $\left[-0.49(10 \mathrm{yr})^{-1}\right]$ and is mainly distributed within the BTC heavy rainstorm interval $(100 \mathrm{~mm} \leq$ BTCER $<250 \mathrm{~mm})$. BTCER occurs mostly from July to September with a peak in August. Three BTCER typical regions - Minbei, the Pearl River Delta (PRD), and Taiwan — are identified according to the clustering of stations with high BTCER frequency and large BTCER. A further analysis of the 850-hPa BTC composite horizontal wind and water vapor flux over the PRD region shows the existence of two water vapor transport channels, which transport water vapor to the western tropical cyclone. In the first of these channels, the transport takes place via the southwest monsoon, which accounts for $58 \%$ of the total moisture, and an easterly flow associated with eastern tropical cyclone accounts for the remaining $42 \%$.
\end{abstract}

Keywords Binary tropical cyclones $\cdot$ Extreme rainfall $\cdot$ China $\cdot$ Water vapor transport

\section{Introduction}

Tropical cyclones (TCs) produced numerous disastrous rainfall events over the coastal regions of the Northwest Pacific Ocean (NWP). Perhaps Typhoon Morakot (2009) was the deadliest TC to impact Taiwan in recorded history; it caused daily precipitation of more than $500 \mathrm{~mm}$ over most of Taiwan, as well as heavy-rainfall-induced secondary disasters such as mountain torrents and debris flows, which destroyed southern Taiwan. Morakot resulted in agricultural losses of more than US\$65 million and around 700 casualties in Taiwan (http://

Responsible Editor: Kyong-Hwan Seo.

Fumin Ren

fmren@163.com

1 School of Atmospheric Sciences, Chengdu University of Information Technology, Chengdu 610225, China

2 State Key Laboratory of Severe Weather, Chinese Academy of Meteorological Sciences, Beijing 100081, China

3 Zhuzhou Meteorological Office, Zhuzhou 412000, Hunan, China

4 Department of Atmospheric Sciences, National Taiwan University, Taipei, Taiwan www.npf.org.tw). In July 2012, Typhoon Saola (2012) impacted the Philippines, causing around 54 fatalities and estimated total economic losses of US\$17.3 million (https://en. wikipedia.org). Subsequently, Saola also impacted China, killing approximately 25 people and causing damage estimated at US\$160 million (https://en.wikipedia.org). Typhoon Fitow (2013) landed at the junction of Zhejiang and Fujian, and brought about exceptionally strong precipitation and storm surges that flooded some areas in Yuyao, Zhejiang, for more than a week. Fitow killed seven people and caused direct economic losses totaling almost 60 billion yuan in October 2013 (http://www.chinanews.com).

Numerous previous studies have examined devastating typhoons like those mentioned above, and found that the anomalous tracks and extreme rainstorms of TCs can be caused by the interaction of two typhoons, together referred to as a binary tropical cyclone (BTC) (Wu et al. 2012; Zhou et al. 2014; Fan et al. 2014; Xu and Du 2015; Yu et al. 2015; Xie et al. 2016; Yu and Su-brahmanyam 2017; Moon and Ha 2019). BTC interaction, also known as the "Fujiwara effect", refers to the phenomenon of two cyclonic vortices, which are situated close to each other, simultaneously performing a mutual counterclockwise spin and gradually moving closer to each other (Fujiwhara 1921, 1923, 1931). 
Numerical model simulations have been used in recent years to study the water vapor and energy transport between BTCs. For instance, Xu et al. (2011) and Wu et al. (2012) pointed out that the existence of Typhoon Goni (2009)'s water vapor transport played an important role in Typhoon Morakot causing heavy rainfall over Taiwan. Xian and Chen (2019) and Xu et al. (2013) conducted model simulations to investigate the BTC interaction between Typhoon Tembin (2012) and Typhoon Bolaven (2012), revealing that the existence of Tembin interrupted the water vapor being transported to Bolaven. Furthermore, several studies have suggested that the moisture transport by Super Typhoon Danas (2013) to Typhoon Fitow (2013) played an important role in the latter's generating the extreme precipitation over Yuyao, Zhejian Province (Xu and Du 2015; Yu et al. 2015; Xie et al. 2016). Despite the above findings, little still remains known about the common characteristics of BTC precipitation, especially extreme precipitation, over China. Accordingly, the purpose of this study is to examine the characteristics and causes of BTC extreme rainfall (BTCER) over China.

The paper is organized as follows: The data and methods are described in Section 2. Section 3 analyzes the temporal and spatial characteristics and main causes of BTCER over China. A summary and concluding remarks are given in the final section.

\section{Data and Methods}

\subsection{Data}

The TC best-track data used in this study are obtained from the Shanghai Typhoon Institute of the China Meteorological Administration for the period 1960-2018. This dataset includes the observed TC location and intensity [MSWS (maximum sustained wind speed) and MSLP (minimum sea level pressure)] in the NWP at 6-h intervals. In this paper, only those TCs whose peak intensity reaches tropical-storm level (MSWS $>17.5 \mathrm{~m} \mathrm{~s}^{-1}$ ) or above are investigated.

Also employed are daily observed precipitation data during the period 1960-2018 over China provided by the National Meteorological Information Center of the China Meteorological Administration, with the measurement coverage ranging from 1200 UTC on the previous day to 1200 UTC on the present day. This dataset includes 2027 rain gauge stations covering most of China, among which 2006 of them are on mainland China and 21 on the island of Taiwan.

The National Centers for Environmental PredictionNational Center for Atmospheric Research (NCEP-NCAR) analysis with $2.5^{\circ} \times 2.5^{\circ}$ grid spacing and 26 vertical layers at 6 -h intervals (i.e., four times per day), including horizontal wind, specific humidity, and geopotential height, is used to examine the large-scale environments in which the BTCs develop.

\subsection{Methods}

The techniques and concepts applied in this study are as follows:

\section{(1) Objective Synoptic Analysis Technique (OSAT)}

The method applied for identifying TC precipitation is the Objective Synoptic Analysis Technique (OSAT, Ren et al. 2001, 2007) that uses the distance from TC center and the closeness and continuity between neighboring raining stations to trace TC-influenced rain belts that may extend from $500 \mathrm{~km}$ to $1100 \mathrm{~km}$ away from a TC center.

\section{(2) An Objective Standard for defining Binary Tropical} Cyclones

An objective standard for defining BTCs developed by Ren et al. (2020) is used in this study to identify BTC pairs in the NWP. The objective standard includes two conditions- the distance between the centers of two coexisting TCs being less than or equal to $1800 \mathrm{~km}$, and the duration being at least $12 \mathrm{~h}$.

\section{(3) Binary Tropical Cyclone Maximum Daily Rainfall}

When examining BTC daily rainfall over land, regardless of being produced by only one or both TCs, a maximum value at a certain station always exists, which refers to the center of the BTC's daily precipitation. We define this maximum value as the BTC maximum daily rainfall.

\section{(4) Binary Tropical Cyclone Extreme Rainfall (BTCER)}

Generally, the definition of extreme precipitation mainly adopts specific thresholds and percentiles (Manton et al. 2001; Zhai et al. 2005; Wang and Zhou 2005), such as R50, R100, R95p, R99p, or other indices. In this study, given that our focus is on the BTC maximum daily rainfall, we define a rainfall as BTCER with two conditions: (1) the rainfall belongs to the BTC maximum daily rainfall; and (2) it is greater than or equal to $50 \mathrm{~mm}$, which is greater than the 95th percentiles of daily precipitation over most parts of China (Zhai et al. 2005; Miao et al. 2015).

(5) Binary Tropical Cyclone Circulation Dynamic Composite Technique (BTCDCT)

Most BTCs are oriented in an east-west arrangement (Ren et al. 2020), and thus a pair of BTCs in this study is simply divided into the eastern-TC and western-TC according to their 
longitudes. Among BTC cases, most western-TCs are relatively close to China. However, directly applying dynamic composite analysis (Gray 1981; Li et al. 2004) to westernTCs will offset the circulation of eastern-TCs. In order to view western-TCs and eastern-TCs holistically, a new technique, Binary Tropical Cyclone Circulation Dynamic Composite Technique (BTCDCT), is proposed in this study. According to a concept put forward by Qian (2012), the BTCDCT technique decomposes total circulation into climatic and anomalous circulations and applies dynamic composite analysis to western-TC circulation and eastern-TC anomalous circulation, respectively. Taking the wind field at $500 \mathrm{hPa}$ as an example, the technique can be illustrated by the following three steps:

Step 1: Dynamic composite analysis for western-TC circulation

For each time during the BTC's duration on a BTCER day, the horizontal wind vector $V(\lambda, \varphi, t)$, where $t, \lambda$ and $\varphi$ represent the time and meridional and zonal variables, respectively, is adopted for dynamic composite analysis to obtain the $V$ $\left(\lambda_{w}, \varphi_{w}\right)_{D_{w}}$ of the western-TC (function 1):

$V(\lambda, \varphi, t) \rightarrow{ }^{\text {dynamic composite }} V\left(\lambda_{w}, \varphi_{w}\right)_{D_{w}}$,

where $\lambda_{w}$ and $\varphi_{w}$ are the meridional and zonal variables, respectively; $D_{w}$ represents the domain of the composite horizontal wind field, which is enclosed by (lat_w- 25 , lat_w +25 ), (lon_w-35, lon_w + 50), where (lat_w, lon_w) is the mean position of western-TCs. The longitude range is set to (lon_w-35, 1on_w +50 ) because $D_{w}$ should contain the corresponding eastern-TC circulation.

Step 2: Dynamic composite analysis for eastern-TC anomalous circulation

A novel approach of decomposing total flow into climatic and anomalous flows was put forward by Qian (2012). According to this concept, the wind field $V(\lambda, \varphi, t)$ is decomposed into the multi-year average climatology horizontal wind field $\bar{V}(\lambda, \varphi, \sqcup)$ and anomalous horizontal wind field $V^{\prime}(\lambda, \varphi, t)$ (function 2):

$V(\lambda, \varphi, t)=V^{\prime}(\lambda, \varphi, t)+\bar{V}(\lambda, \varphi, \sqcup)$.

Applying the dynamic composite analysis method to $t$ eastern-TC anomalous circulations, the composite anomalous horizontal wind field $V^{\prime}\left(\lambda_{\mathrm{e}}, \varphi_{\mathrm{e}}\right)_{D_{e}}$ of eastern-TCs is obtained (function 3). The $\lambda_{\mathrm{e}}$ and $\varphi_{\mathrm{e}}$ are the new meridional and zonal variables, respectively. $D_{e}$ represents the domain of the composite anomalous horizontal wind field, which is enclosed by (lat_e-25, lat_e+25) and (lon_e-50, lon_e+35), where (lat_e, lon_e) is the mean position of $t$ eastern-TCs. The longitudinal range is set to (lon_e-50, 1on_e +35 ) because $D_{e}$ should contain the corresponding western- $\mathrm{TC}$ anomalous circulation:

$V^{\prime}(\lambda, \varphi, t) \rightarrow{ }^{\text {dynamic composite }} V^{\prime}\left(\lambda_{\mathrm{e}}, \varphi_{\mathrm{e}}\right)_{D_{e}}$.

\section{Step 3: BTC circulation composite}

Through interpolation, the two composite wind fields with different longitude and latitude variables are interpolated into two wind fields with the same longitude and latitude variables. The two composite fields are superimposed to obtain the BTC composite wind field $\widetilde{V}\left(\lambda_{b}, \varphi_{b}\right)_{D_{b}}$ (function 4), where $\varphi_{\mathrm{b}}$ and $\lambda_{\mathrm{b}}$ represent the meridional and zonal variable of the BTC composite wind field respectively, and $D_{b}$ is the target area $\left(0^{\circ}-45^{\circ} \mathrm{N}, 85^{\circ}-155^{\circ} \mathrm{E}\right)$ in this study:

$V\left(\lambda_{w}, \varphi_{w}\right)_{D_{w}}+V^{\prime}\left(\lambda_{\mathrm{e}}, \varphi_{\mathrm{e}}\right)_{D_{e}} \rightarrow^{\text {interpolate }} \widetilde{V}\left(\lambda_{b}, \varphi_{b}\right)_{D_{b}}$.

By using this method, the general characteristics of BTC circulation are retained, and the surrounding large-scale circulation can almost stay intact.

\section{Results}

\subsection{Temporal Characteristics of BTCER}

During 1960-2018, 427 pairs of BTC formed in the NWP, 258 of which had an impact on China (Fig. 1). Among these 258 BTCs, the rainfall of 36 BTCs is below the interval of a BTC rainstorm $(<50 \mathrm{~mm})$, while the rainfall of 222 fell into the range of BTCER ( $\geq 50 \mathrm{~mm}$ ). A total of $106 \mathrm{BTCs}$ produced the daily rainfall amounts that fell into the range of a BTC heavy rainstorm (i.e., $100 \mathrm{~mm} \leq$ BTCER $<250 \mathrm{~mm}$ ), witch accounting for $47.7 \%$ of all BTCER; Note that the mean daily amount of $203.3 \mathrm{~mm}$ for all BTCER events appeared in

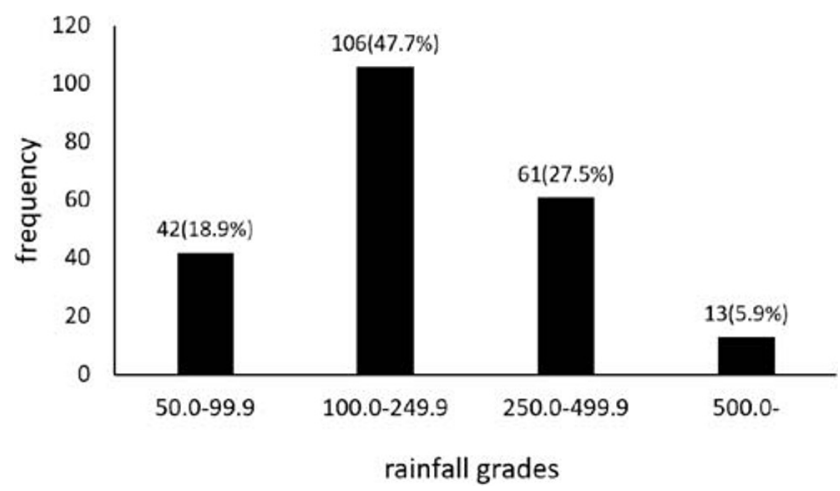

Fig. 1 Grade-frequency distribution of BTCER (units: $\mathrm{mm}$ ) over China from 1960 to 2018 
this heavy rainstorm range. A total of $61(27.5 \%)$ and 42 (18.9\%) BTCER occur in the interval of a BTC severe rainstorm $(250 \mathrm{~mm} \leq \mathrm{BTCER}<500 \mathrm{~mm})$ and BTC rainstorm $(50 \mathrm{~mm} \leq$ BTCER $<100 \mathrm{~mm})$ respectively. Furthermore, 13 (5.9\%) BTCER are above $500 \mathrm{~mm}$ during this time period, seven of which occurred in 2000 or later.

Figure 2 shows the time series of BTCER frequency along with its linear trend. The highest frequency of BTCER appears in 1960 and 1973, both with a frequency of 12. In 2005 and 2014, there were no BTCER due to no BTC pairs impacting China. After 2000, only 2018 ranks among the top 10 BTCER high-frequency years, while the 1960s and 1970s account for six of them. As we can see from the dotted line, the BTCER frequency decreases at a rate of $0.49(10 \mathrm{yr})^{-1}$, which is statistically significant at the 0.05 level, suggesting that the frequency of BTCER over China has decreased. This decrease in BTCER frequency may be due to the decreasing trend of the frequency of influential TCs in China (Ren et al. 2006).

As shown in Fig. 3, the seasonal variation of BTCER in China shares similar characteristics to the TC activity (Sun et al. 2010), with the BTCER season generally being from May to November. BTCER starts to affect China on 26 May, and ends on 24 November. The frequency of BTCER is distributed near-symmetrically before and after the peak month of August, with most occurrences from July to September, accounting for $84.2 \%$ of the total.

BTCER's larger values tend to occur in July, August, October, and November, with the largest value set by Typhoon Goni (2009) and Typhoon Morakot (2009) in August (Fig. 4). The second-largest BTCER occurred in October 1978 and was set by Typhoon Nina (1978) and Typhoon Ora (1978), while the third-largest occurred in November 2000, set by Typhoon Xangsane (2000) and Bebinca (2000).

\subsection{Spatial Characteristics of BTCER}

The spatial distribution of intensity and frequency are of the main concern in this study of the general

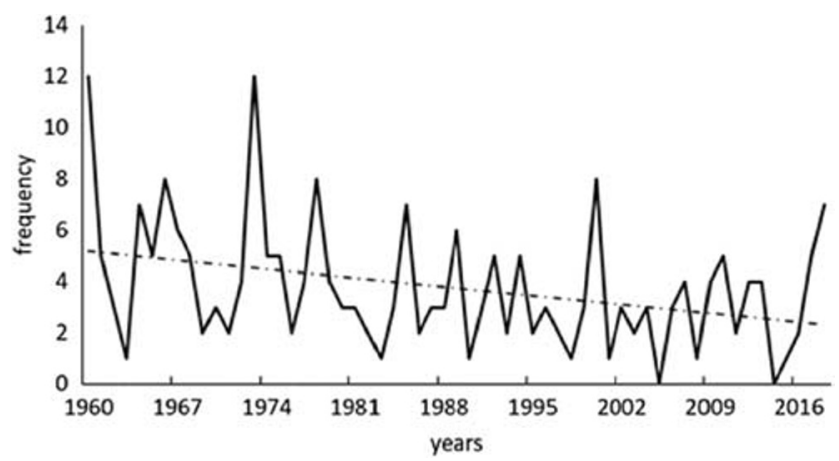

Fig. 2 Annual variations of BTCER frequency over China during 19602018. The dotted line represents the linear trend during the period

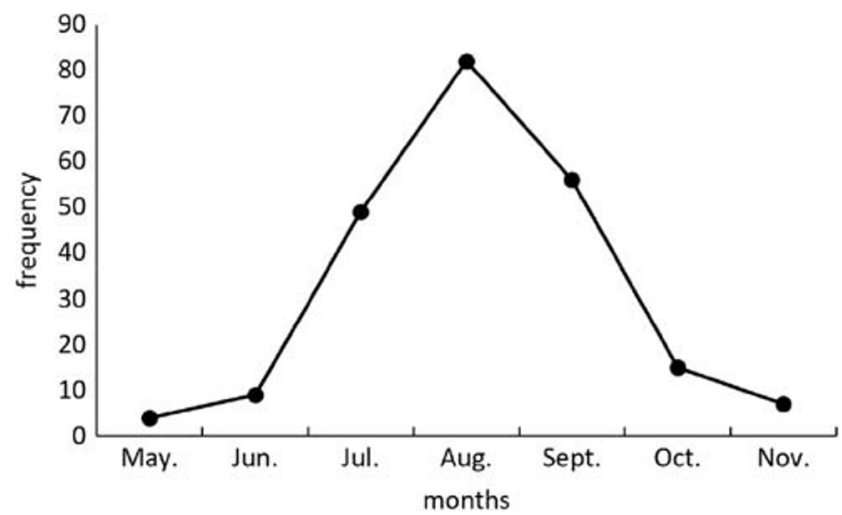

Fig. 3 Seasonal variation of BTCER frequency during 1960-2018 over China

characteristics of BTCER over China. It is evident from Fig. 5a that BTCER occurs at most stations on the islands of Taiwan and Hainan, but mainly in the central and eastern parts of mainland China, i.e., roughly to the east of $106^{\circ} \mathrm{E}$. The largest BTCER frequency is 18 takes place at Anbu station, Taiwan, and the station with the secondhighest frequency of 17 is Alishan station, Taiwan. The largest BTCER frequency for mainland China is at Hong Kong station, Dinghai station, and Dafeng station-each with a frequency of 4 . Lingshui station, with a frequency of 3, has the highest BTCER frequency on Hainan Island. Bounded by the Central Mountain Range of Taiwan, stations in eastern Taiwan have a BTCER frequency that is much higher than stations in western Taiwan. It is also evident that stations with high BTCER frequencies (i.e., $>1$ ) are clustered in a relatively small areas of northern Fujian, and the Pearl River Delta (PRD).

Figure $5 \mathrm{~b}$ presents the distribution of maximum BTCER over China during 1960-2018. Most stations in Taiwan have large BTCER, with four stations along the Central Mountain Range having a value exceeding $500 \mathrm{~mm}$. In mainland China a BTCER exceeding $500 \mathrm{~mm}$ only occurs at Beihai station. The distribution

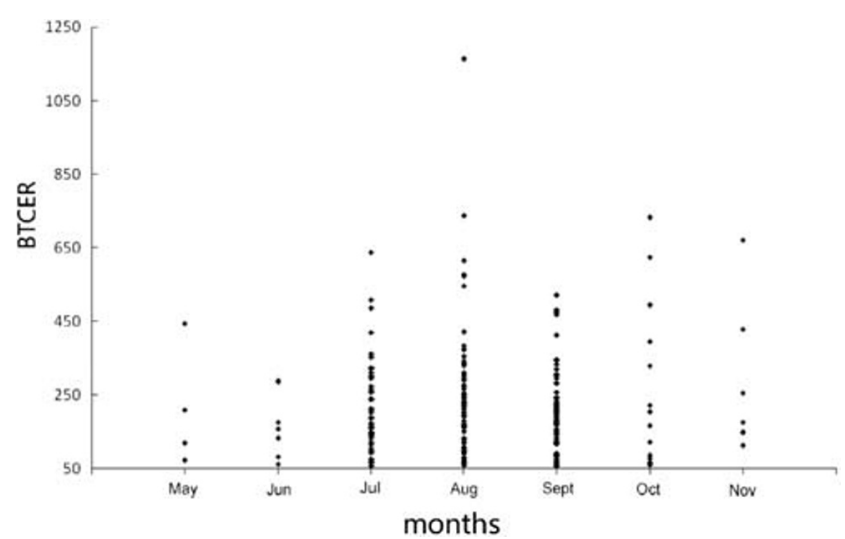

Fig. 4 Time (month)-BTCER (units: $\mathrm{mm}$ ) cross section over China during 1960-2018 

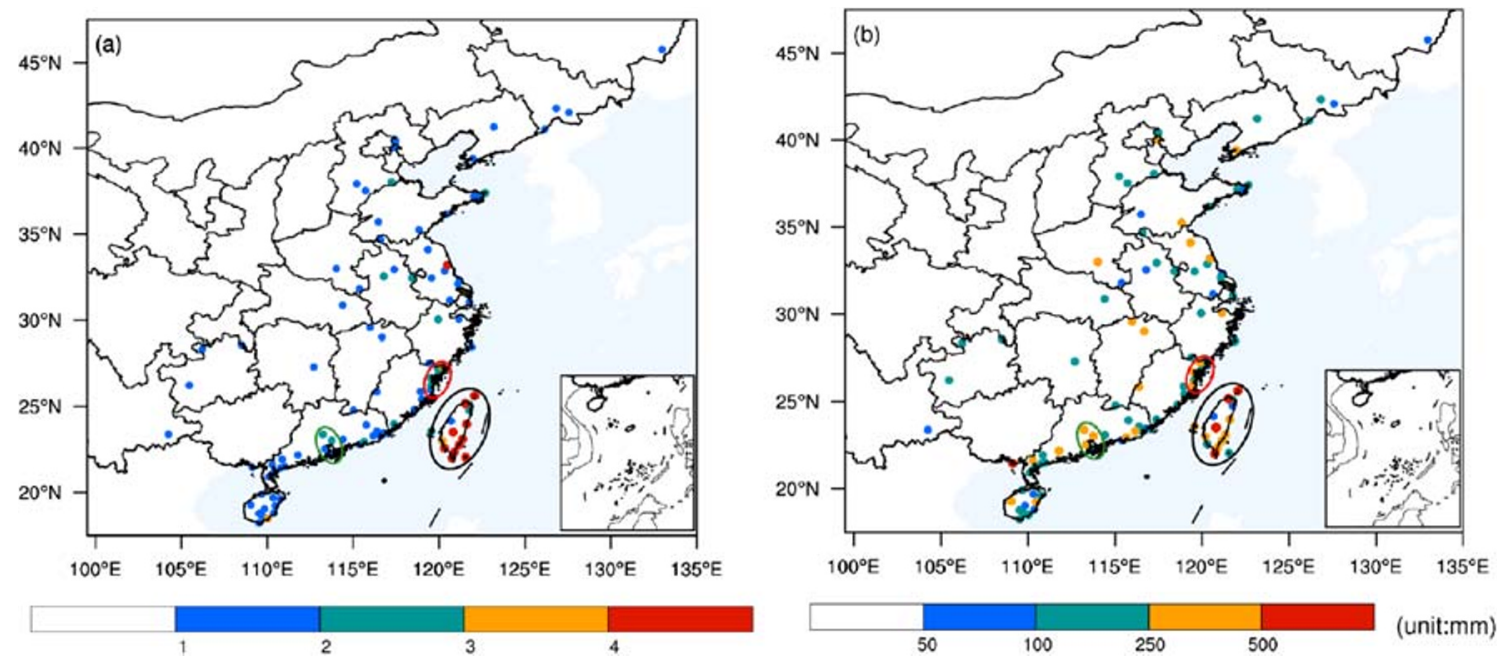

Fig. 5 Spatial distribution of BTCER statistics over China during 1960-2018: (a) frequency of BTCER; (b) maximum BTCER; Red cycle: Minbei region; Forestgreen cycle: $\mathrm{PRD}$ region; Black cycle: Taiwan region

of maximum BTCER shares similar characteristics to the BTCER frequency distribution. Stations with large BTCER are concentrated on Taiwan and along the east and south coast of mainland China. It can be seen that 6 stations with a BTCER no less than $100 \mathrm{~mm}$ are concentrated in a relatively small area of northern Fujian Province, and 6 stations with a BTCER no less than $100 \mathrm{~mm}$ are also densely distributed in the PRD region. Moreover, when we focus on BTC accumulated precipitation over China, the distributions of high-frequency and large are almost in complete accordance with the distribution of BTCER (figure not shown).

Considering stations with high BTCER frequency and large BTCER are concentrated in a relatively small area in northern Fujian Province and the PRD region as well as on Taiwan Island, we select the area covered by the stations of Fuding, Zherong, Xiapu, Ningde and Lianjiang as typical of high BTCER frequency and large BTCER and refer to it as the "Minbei" typical area. Similarly, we choose the area covered by the stations of Hong Kong, Macao, Dongguan, Zhuhai, Zhongshan and Huadu, and name this as the "PRD" typical region. In addition, Taiwan Island is also defined as another typical region (see the three ovals in Fig. 5).

Actually, the topography of these three typical regions is highly unique. Niu et al. (2010), Ye et al. (2018) and Qiu et al. (2019) indicated that topographical forcing is the main cause of TC torrential rainfall in the Minbei region. Similarly, Zhao et al. (2008), Li et al. (2013) and Xu et al. (2018) concluded that the trumpet-shaped topography of the PRD region makes it vulnerable to typhoon-related extreme rainfall. Moreover, Lin et al. (2002), Xie and Zhang (2012) and Chen et al. $(2017 \mathrm{a}, \mathrm{b})$ pointed out that the interaction between the Central Mountain Range of Taiwan with typhoon circulation is very important for the occurrence of associated extreme precipitation over the island.

\subsection{Causes of BTCER in Typical Regions}

In order to investigate the main causes of BTCER occurring frequently in the three typical areas, some diagnostic analysis is carried out.

The seasonal variation is an important factor that influences typhoon rainfall. During 1960-2018, BTCER occurred 12 times in the Minbei region, with an average BTCER of $196.3 \mathrm{~mm}$; 11 times in the PRD region with an average of $230.2 \mathrm{~mm}$, and 106 times in Taiwan with an average of $275.0 \mathrm{~mm}$ (Table 1). The months of July and August, September, and August have the highest BTCER frequency for Minbei, PRD and Taiwan, respectively.

The Northwest Pacific subtropical high (NWPSH) not only affects the moving path of typhoons, but also influences their precipitation. Exploring the distribution of BTC locations and the circulation of the NWPSH is of great importance for diagnosing the preliminary causes of BTCER. Figure 6a-c show the distributions of the locations of BTC pairs on BTCER days and their mean

Table 1 Seasonal variations of BTCER frequency during 1960-2018 over three typical regions

\begin{tabular}{llll}
\hline & Minbei & PRD & Taiwan \\
\hline May & & & 2 \\
Jun. & 4 & 1 & 2 \\
Jul. & 4 & 2 & 22 \\
Aug. & 2 & 2 & 36 \\
Sep. & 2 & 1 & 30 \\
Oct. & 12 & & 8 \\
Nov. & & 11 & 6 \\
Total & & & 106 \\
\hline
\end{tabular}



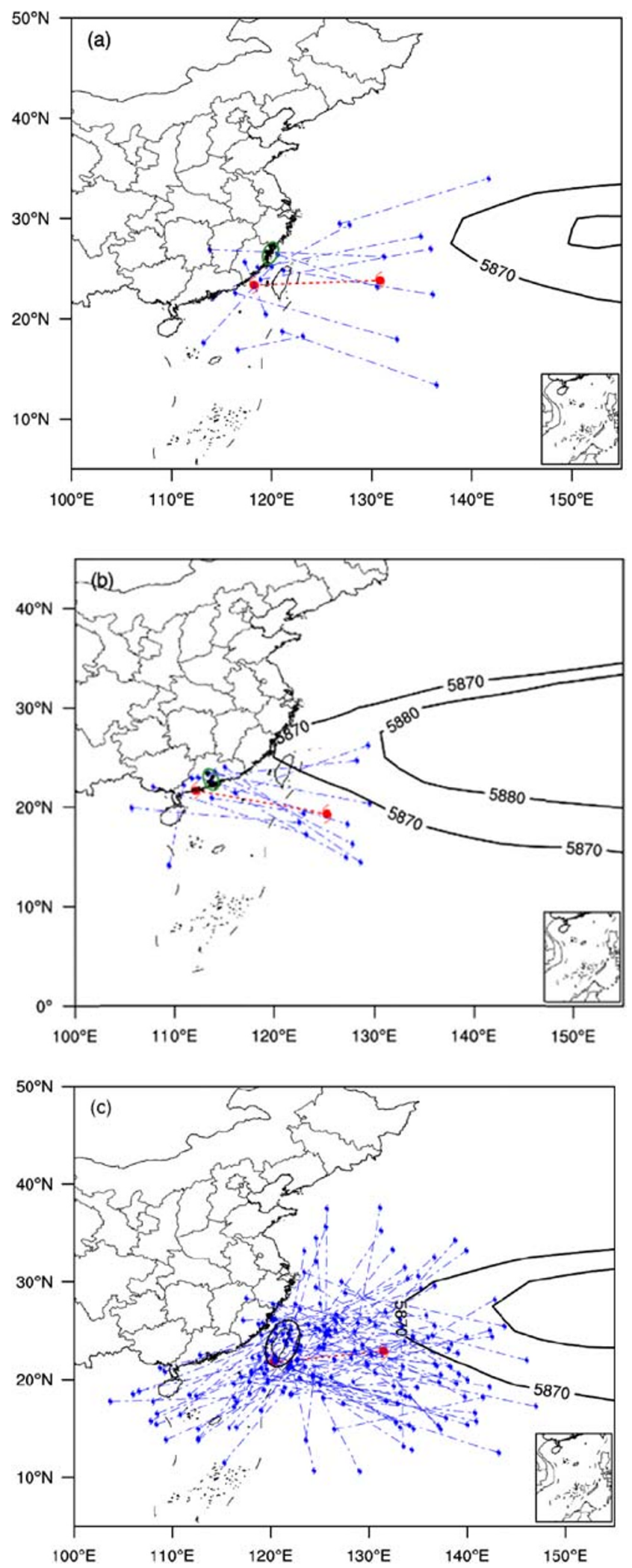

position associated with the three clustered BTCER regions, respectively, along with the average position of the NWPSH in the month of the BTCER occurrences.
Fig. 6 Positions of BTCs (two blue typhoon symbols connected by blue dashed lines) and their mean position (two red typhoon symbols connected by red dotted line), along with the average position of the $500 \mathrm{hPa}$ Northwest Pacific subtropical high in the month of BTCER occurrence over the three typical regions from 1960 to 2018: (a) Minbei region; (b) PRD region; (c) Taiwan region

As Fig. 6a shows, the mean position of western-TCs in the Minbei region is located in the south of the East Asian monsoon region (i.e., $20^{\circ}-40^{\circ} \mathrm{N}, 110^{\circ}-125^{\circ} \mathrm{E}$ ), where ample water vapor is present (Huang et al. 1998). Moreover, the mean position of western-TCs is $102.90 \mathrm{~km}$ away from the coastline of Fujian Province and about $400 \mathrm{~km}$ to the southwest from the central Minbei region a configuration that would likely bring rainstorms induced by an inverted trough of the western-TC to the Minbei region (Chen et al. 2017a, b), whereas, the NWPSH could hardly have any significant effect on the development western-TC. Statistically, the mean intensities of the western-TCs and the eastern-TCs are $32.6 \mathrm{~m} \mathrm{~s}^{-1}$ and $24.9 \mathrm{~m} \mathrm{~s}^{-1}$, respectively; and their mean position are about $1280 \mathrm{~km}$ apart with an east-west orientation. The Minbei region is located in the first quadrant of the mean western-TC position, and this configuration is conducive to the production of inverted-trough precipitation by the western-TCs (Chen and $\mathrm{Xu}$ 2017). In addition, the presence of the eastern-TCs appears to transport water vapor flux into western-TCs in the lower troposphere, as given in Fig. 7a showing that on average the water vapor flux of the western-TC is mainly from the westward moisture transfer through the eastern-TC. Based on above analyses, besides the characteristics of the westernTC such as its position and intensity, environmental factors for the occurrence of BTCER in this region might mainly be the westward transfer of moisture from the eastern-TC and its strong intensity.

The position of BTC pairs causing BTCER events over the PRD typical region shows a relatively consistent northeastsouthwest arrangement. Most of western-TCs are close to the PRD region (Fig. 6b). The mean position of western-TCs is only $42.41 \mathrm{~km}$ from the coastline of Guangdong Province, and less than $200 \mathrm{~km}$ from the center of the PRD region. The NWPSH is strong and extends westwards to mainland China. Besides, the mean position of BTCs demonstrates an east-northeastern to west-southwestward direction, which is almost parallel to the contour of $5870 \mathrm{gpm}$ in the southwest of the NWPSH.

Based on the configuration of BTCs and the NWPSH and some of above analyses, we can discuss the main causes of BTCER in the PRD region. Firstly, western-TCs are positioned so close (less than $100 \mathrm{~km}$ ) to the PRD region, implying extreme precipitation near the western-TC's eyewall might impact this region severely. Secondly, the streamline of the southwest periphery of the NWPSH tends to steer the BTC to move westwards (Fig. 6b). The northwestward streamline together with the eastern-TC transfer moisture and energy to the western-TC, 
Fig. 7 Distribution of BTC composite horizontal wind (vectors; units: $\mathrm{m} \mathrm{s}^{-1}$ ) and vapor flux [shaded; units: $\mathrm{g}$ $(\mathrm{cm} \mathrm{hPa} \mathrm{s})^{-1}$ ] fields at $850 \mathrm{hPa}$ for BTCs. a Minbei region; b PRD region; (red line: the section used for calculating the water vapor transport)
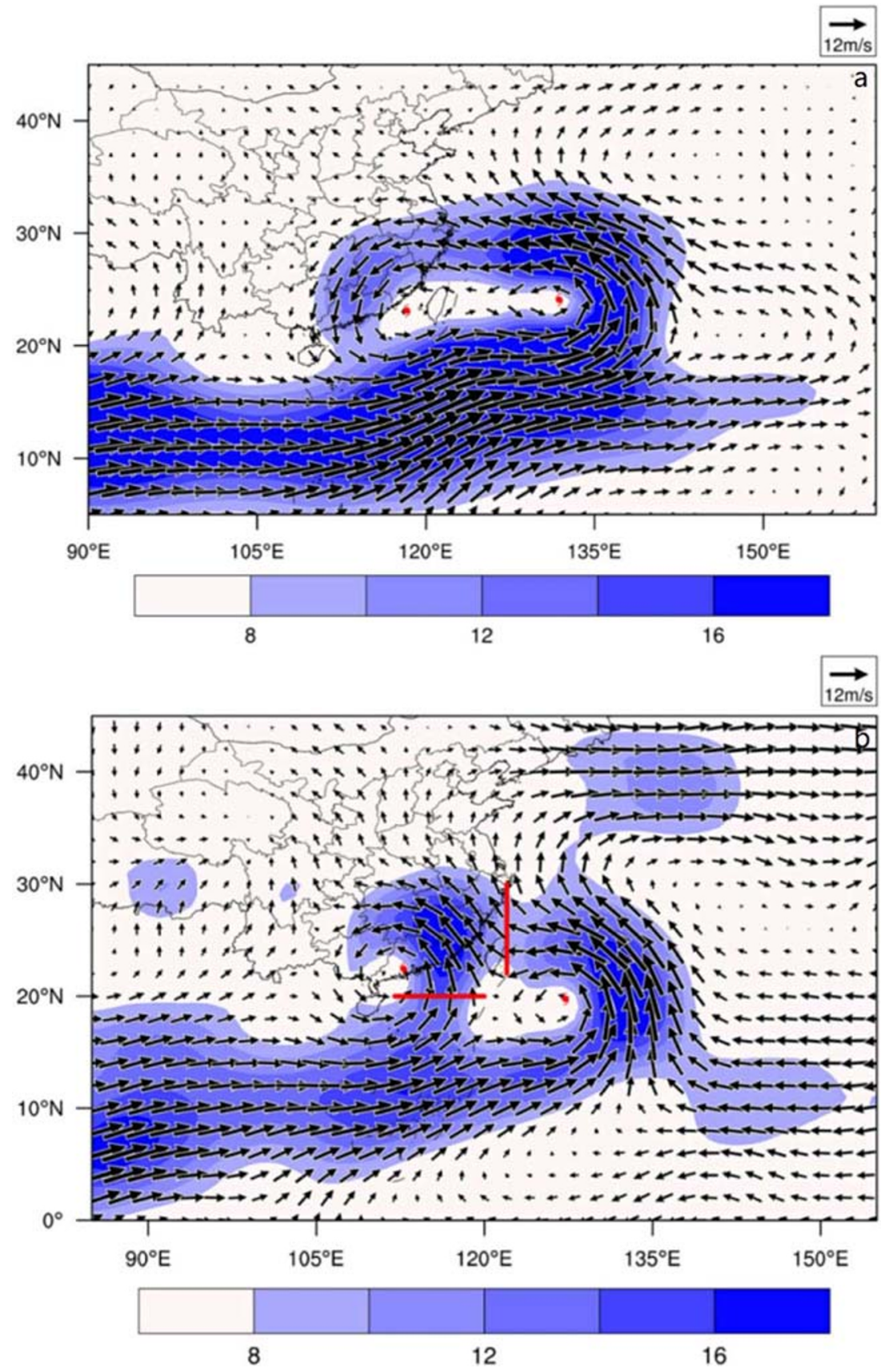

resulting in sufficient water vapor in the PRD region (Fig. 7b). Furthermore, during the period of BTCER occurrence, the southwest monsoon prevails over the area where the westernTC is located, meaning there is a high probability of the western-TC being impacted by the monsoon surge. The moisture and energy transported by the southwest monsoon causes the extreme rainfall produced by the western-TC to be maintained in the PRD typical region (Chen et al. 2017a, b).

As Fig. 6c shows, the distributions of BTC pairs caused BTCER events in the Taiwan typical region to be mainly eastwest arranged; however, there are also many BTCs distributed in the north-south direction. Western-TCs are not always closer than eastern-TCs to the Taiwan typical region. The average NWPSH is weak, and located far away from the Taiwan region during the period of BTCER occurrence. This could help explain partly why the distributions and orientations of the BTCs are less organized than those associated with the PRD regional BTCER.

The distribution of BTCs affecting the Taiwan region is relatively complex. Thus, simply dividing BTCs into western-TCs and eastern-TCs is not a reasonable approach. In addition, since the Taiwan island involves complex terrain with unusual land-water contrasts, the mechanisms by which BTCER occurs are quite different from those in the other two 
regions. Thus, the main causes of BTCER need further investigation in future studies. The following only takes the PRD typical region as an example to explore the causes of BTCER in this region from the perspective of binary tropical interaction.

The continuous transportation of sufficient water vapor and energy to maintain typhoon precipitation is a necessary condition for the occurrence of BTCER. As Fig. 7b shows, the western-TCs in the PRD region have two strong water vapor transport channels. One is the transport of the southwest monsoon, which originates from the low latitudes of the Indian Ocean, crosses the Indochina Peninsula, and brings a large amount of water vapor from the South China Sea. The other is a strong easterly wind associated with the NWPSH and eastern-TC that carries water vapor from the NWP to western-TC. In order to quantify the water vapor transport capacity of the two channels, we intercept the southwest monsoon water vapor transport channel at $20^{\circ} \mathrm{N}$ and the eastern-TC water vapor transport channel at $122^{\circ} \mathrm{E}$, and then calculate the water vapor flux integral of the two intercepts. Result shows that the contribution of the southwest monsoon channel accounts for $58 \%$ of the total transport, while the eastern-TC's accounts for the remaining $42 \%$. These two water vapor transport channels continuously transport water vapor and energy to the western$\mathrm{TC}$ and, together with the trumpet-shaped topography, contributing to the extreme precipitation over the PRD region.

\section{Summary and Discussion}

The characteristics of BTCER over China and their main causes are investigated using NCEP-NCAR reanalysis data, station precipitation data, and TC best-track data. The following conclusions can be drawn based on the above analyses:

(1) During 1960-2018 there have been 222 occurrences of BTCER in China, with annual frequency varying from 12 to null and a mean annual frequency of 3.76; but it exhibited a decreasing trend of $\left[-0.49(10 \mathrm{yr})^{-1}\right]$. BTCER mainly occurred in the BTC heavy rainstorm interval, accounting for $47.7 \%$ of total BTCERs. BTCER mostly appeared in July to September, with the peak in August. In addition, BTCER with relatively larger amounts tend to occur in the months of August, October and November.

(2) It is found that BTCER occurred over the southern and eastern coastal regions of China, and the islands of Taiwan and Hainan. However, clustered BTCER events with high frequencies and large amount were observed in Minbei, the PRD and Taiwan island, e.g., with 12, 11, and 106 times, respectively, during the 59-year period. The clustered BTCER events over the former two regions were mostly produced by the western-TCs of
BTCs, and the PRD events were more related to eyewall convection of landfalling western-TCs. In this regard, the Minbei and PRD regional BTCER could be significantly influenced by the eastern-TCs through the moisture transport. We speculate that local topography could be one of the major external factors accounting for the clustered BTCER events over the three regions, as indicated by the low-level winds with a significant component perpendicular to the coastline and local topography (figure omitted).

(3) Since the PRD regional BTCER events are more related to eyewall convection of landfalling western-TCs, an analysis of the 850-hPa BTC composite horizontal winds and water vapor transport into the PRD region is performed. Result shows that the presence of two water vapor transport airstreams into the western portion of BTC's circulation. One is the southwesterly monsoonal airstream accounting for $58 \%$ of the total water vapor in the lower troposphere, and the other is the easterly flow accounting for the remaining $42 \%$ that is more associated with eastern-TCs. These two airstreams continuously transport water vapor and energy to the western-TC and, together with the trumpet-shaped topography, can cause continuous extreme precipitation over the PRD region.

This study reveals some of the main characteristics of BTCER in China, especially the water vapor transport between BTCs plays an important role for the occurrence of BTCER. Meanwhile, according to our statistics, BTCs and non-BTCs had no significant difference in the probability of extreme rainfall occurrence. This may due to the typhoon itself is a very strong system, and generally BTC interaction might not be dominant for the precipitation. However, there are still some limitations to the results that require further study. For instance, the decreasing trend of BTCER frequency might be attributed to the interdecadal change in typhoon genesis over the WNP (Choi et al. 2015; Kim et al. 2019). In addition, the main causes of BTCER in the Taiwan region is of a great concern, and an exploration analysis reveals that classification statistics on the directions of the line segments between the two TCs for each BTCs may be a reasonable way to deal with the problem. Finally, this paper focuses on diagnostic analysis, but the physical mechanisms of some of the conclusions need to be verified through numerical simulations. Above further studies need to be carried out in the near future.

Acknowledgements This work was supported by the National Key R\&D Program of China (Grant No. 2018YFC1507703), the National Natural Science Foundation of China (Grant No. 41675042), the Hainan Provincial Key R\&D Program of China (SQ2019KJHZ0028), project "dynamical-statistical ensemble technique for predicting landfalling tropical cyclones precipitation", and the Jiangsu Collaborative Innovation Center for Climate Change. 
Open Access This article is licensed under a Creative Commons Attribution 4.0 International License, which permits use, sharing, adaptation, distribution and reproduction in any medium or format, as long as you give appropriate credit to the original author(s) and the source, provide a link to the Creative Commons licence, and indicate if changes were made. The images or other third party material in this article are included in the article's Creative Commons licence, unless indicated otherwise in a credit line to the material. If material is not included in the article's Creative Commons licence and your intended use is not permitted by statutory regulation or exceeds the permitted use, you will need to obtain permission directly from the copyright holder. To view a copy of this licence, visit http://creativecommons.org/licenses/by/4.0/.

\section{References}

Chen, L., Xu, Y.: Review of typhoon very heavy rainfall in China. Meteor. Environ. Sci. 40, 3-10 (2017) (in Chinese with English abstract)

Chen, J., Ping, F., Wang, X., et al.: Topographic influence of Taiwan Island on typhoon "Matmo". Chin. J. Atmos. Sci. 41, 1037-1058 (2017a) (in Chinese with English abstract)

Chen, L., Meng, Z., Cong, C.: An overview on the research of typhoon rainfall distribution. J. Marine Meteor. 37, 1-7 (2017b) (in Chinese with English abstract)

Choi, Y., Ha, K., Ho, C., et al.: Interdecadal change in typhoon genesis condition over the western North Pacific. Clim. Dyn. 45, 3243-3255 (2015). https://doi.org/10.1007/s00382-015-2536-y

Fan, A., Luo, X., Peng, X., et al.: Impact of typhoon "Damery" on typhoon "Saola". Mar. Forec. 31, 26-34 (2014) (in Chinese with English abstract)

Fujiwhara, S.: The natural tendency towards symmetry of motion and its application as a principle of motion. Quart. J. Roy. Meteor. Soc. 47, 287-293 (1921)

Fujiwhara, S.: On the growth and decay of vortical systems. Quart. J. Roy. Meteor. Soc. 49, 75-104 (1923)

Fujiwhara, S., 1931: Short note on the behavior of two vortices. Proc. Phys. Math. Soc. Japan, Ser. 3, 13, 106-110

Gray, W. M., 1981: Recent advances in tropical cyclone research from rawinsonde composite analysis. WMO Program on Research in Tropical Meteorology. Fort Collins, Colorado, $407 \mathrm{p}$

Huang, R., Zhang, Z., Huang, G., et al.: Characteristics of the water vapor transport in east Asian monsoon region and its difference from that in south Asian monsoon region in summer. Acta Meteor. Sinica. 22, 460-469 (1998) (in Chinese with English abstract)

Kim, H., Seo, K., Yeh, S., et al.: Asymmetric impact of Central Pacific ENSO on the reduction of tropical cyclone genesis frequency over the western North Pacific since the late 1990s. Clim. Dyn. 54, 661-673 (2019). https://doi.org/10.1007/ s00382-019-05020-8

Li, Y., Chen, L., Wang, J.: The diagnostic analysis on the characteristics of large scale circulation corresponding to the sustaining and decaying of tropical cyclone after it's landfall. Acta. Meteor. Sinica. 62, 167-179 (2004) (in Chinese with English abstract)

Li, B., Liu, L., Zhao, S., et al.: Numerical experiment of the effect of local low terrain on heavy rainstorm of South China. Plateau Meteor. 32, 1638-1650 (2013) (in Chinese with English abstract)
Lin, Y., Ensley, D., Chiao, S., et al.: Orographic influences on rainfall and track deflection associated with the passage of a tropical cyclone. Mon. Weather Rev. 130, 2929-2950 (2002)

Manton, M., Della-Marta, P., Haylock, M., et al.: Trend in extreme daily rainfall and temperature in Southeast Asia and the South Pacific:196-11998. Int. J. Climatol. 21, 269-284 (2001)

Miao, C., Ashouri, H., Hsu, K.-L., et al.: Evaluation of the PERSIANNCDR daily rainfall estimates in capturing the behavior of extreme precipitation events over China. J. Hydrometeorol. 16, 1387-1396 (2015)

Moon, M., Ha, K.: Effect of typhoon-generated cold wake on the subsequent typhoon Tembin and its sensitivity to horizontal resolutions. Atmosphere (Basel). 10, 644 (2019). https://doi.org/10.3390/ atmos10110644

Niu, X., Du, H., Teng, D., et al.: Main factors affecting the rainfall caused by landing typhoons. Torrential Rain and Disasters. 29, 78-82 (2010) (in Chinese with English abstract)

Qian, W.: Physical decomposition principle of regional-scale atmospheric transient anomaly. Chin. J. Geophys. 55, 1439-1448 (2012)

Qiu, W., Ren, F., Wu, L., et al.: Characteristics of tropical cyclone extreme precipitation and its preliminary causes in Southeast China. Meteorog. Atmos. Phys. 131, 613-626 (2019)

Ren, F., Gleason, B., Easterling, D.: A numerical technique for partitioning cyclone tropical precipitation. J. Trop. Meteorol. 17, 308-313 (2001) (in Chinese with English abstract)

Ren, F., Wu, G., Dong, W., et al.: Changes in tropical cyclone precipitation over China. Geophys. Res. Lett. 33, 131-145. L20702 (2006). https://doi.org/10.1029/2006GL027951

Ren, F., Wang, Y., Wang, X., et al.: Estimating tropical cyclone precipitation from station observations. Adv. Atmos. Sci. 24, 700-711 (2007)

Ren, F., Y. Xie, B. Yin, and et al., 2020: Establishment of an objective standard for the definition of binary tropical cyclones. Advances in Atmospheric Sciences, submitted

Sun, L., Ai, W., Song, W., et al.: Study on climatological characteristics of China-influencing tropical cyclones. J. Trop. Meteorol. 26, 60-64 (2010) (in Chinese with English abstract)

Wang, Y., Zhou, L.: Observed trends in extreme precipitation events in China during 1961-2001 and the associated changes in large-scale circulation. Geophys. Res. Lett. 32, L09707 (2005). https://doi.org/ 10.1029/2005GL022574

Wu, X., Fei, J., Huang, X., et al.: A numerical study of the interaction between two simultaneous storms: Goni and Morakot in September 2009. Adv. Atmos. Sci. 29, 561-574 (2012)

Xian, Z., Chen, K.: Numerical analysis on the effects of binary interaction between typhoons Tembin and Bolaven in 2012. Adv. Meteorol. 2019, ID 7529263, (2019). https://doi.org/10. $1155 / 2019 / 7529263$

Xie, B., Zhang, F.: Impacts of typhoon track and island topography on the heavy rainfalls in Taiwan associated with Morakot (2009). Mon. Weather Rev. 140, 3379-3394 (2012). https://doi.org/10.1175/ MWR-D-11-00240.1

Xie, H., Ren, F., Li, G., et al.: Role of supper typhoon Danas in the extreme precipitation caused by severe typhoon Fitow. Meteorol. Monogr. 42, 156-165 (2016) (in Chinese with English abstract)

Xu, H., Du, B.: The impact of typhoon Danas (2013) on the torrential rainfall associated with typhoon Fitow (2013) in East China. Adv. Meteorol. 1-11 (2015)

$\mathrm{Xu}, \mathrm{X} ., \mathrm{Lu}, \mathrm{C} ., \mathrm{Xu}, \mathrm{H}$., et al.: A possible mechanism responsible for exceptional rainfall over Taiwan from typhoon Morakot. 
Atmos. Sci. Lett. 12, 294-299 (2011). https://doi.org/10.1002/ asl.338

Xu, J., Guo, J., Huang, N.: Diagnostic analysis of intensity and path changes of the no.1215 typhoon "Bolaven". J. Nat. Dis. 22, 203-209 (2013) (in Chinese with English abstract)

$\mathrm{Xu}, \mathrm{J} ., \mathrm{Bi}, \mathrm{B}$., Chen, Y., et al.: Mesoscale characteristics and mechanism analysis of the unexpected local torrential rain in Guangzhou on 7 May 2017. Acta Meteor. Sinica. 76, 511-524 (2018) (in Chinese with English abstract)

Ye, L., Shen, Y., Li, S., et al.: Mesoscale analysis on rainfalls associated with typhoon Soudelor (1513) in different stages. J. Trop. Meteorol. 34, 371-382 (2018) (in Chinese)

Yu, S.Y., Su-brahmanyam, M.V.: Rainfall variations due to twin typhoons over north- West Pacific Ocean. Open Access Library Journal. 4, e3638 (2017)
Yu, Z., Ji, C., Xu, J., et al.: Numerical simulation and analysis of the Yangtze River Delta rainstorm on 8 October 2013 caused by binary typhoons. Atmos. Res. 166, 33-48 (2015)

Zhai, P., Zhang, X., Wan, H., et al.: Trends in total precipitation and frequency of daily precipitation extremes over China. J. Clim. 18, 1096-1108 (2005)

Zhao, Y., Li, Z., Xiao, Z., et al.: A diagnostic and numerical study on a rainstorm in South China induced by a northwardpropagating tropical system. J. Meteor. Res. 22, 284-302 (2008) (in Chinese with English abstract)

Zhou, F., Qian, Y., Zhu, X., et al.: Cause analysis on the severe rainfall in Zhejiang during the weakening of Fitow. Meteorol. Monogr. 40, 930-939 (2014) (in Chinese with English abstract)

Publisher's Note Springer Nature remains neutral with regard to jurisdictional claims in published maps and institutional affiliations. 